\title{
GENERAL ASPECTS OF A STUDY ON THE REGIMEN \\ OF LAKE MARACAIBO
}

\author{
G. A. McCammon \\ Creole Petroleum Corporetion \\ Caracas, Venezuela
}

Maracaibo Basin in Western Venezuela, Figure 1, has an area of 90,000 square kilometers. It is isolated from the rest of Venezuela on the East and south, and from Columbia on the West, by mountain ranges which reach a height of 5,000 meters at the southern boundary of the Basin. Lake Maracaibo and its marginal swamps cover 17,700 square kilometers of the Basin. The Lake proper, approximately $150 \mathrm{kilometers} \mathrm{long} \mathrm{by} 110 \mathrm{kilometers} \mathrm{wide,} \mathrm{is} \mathrm{connected} \mathrm{to} \mathrm{the}$ Gulf of Venezuela by the Straits of Maracaibo and broad shallow Tablazo Bay. It is about 50 kilometers from the lake proper to the gulf. Tablazo Bay is separated from the Gulf of Venezuela by a series of shifting sand islands and bars.

The Lake Maracaibo Basin contains one of the world's large oil fields. Creole Petroleum Corporation as the largest producer of oil from this area, has a deep interest in all the factors which affect the region. From time to time w have investigated the phenomenon of nature. The principal characteristics of the region which have been studied so far are: the climate, rain fall, lake currents, lake salinity, tides, and the action of the channels and bars between the lake and the Gulf of Venezuela.

Since the entrance conditions to the lake vitally affected the transport of oil from the fields to the world's markets they were the first to be studied by the oil companies. When oil started moving out of Lake Maracaibo the draft of the vessels was limited to nine feet by an outer and inner bar, Figure 2. The channel across the outer bar was not fixed because of the shifting sand, generally the channel moved from east to west until it reached an extreme position and raopened a new channel to the east.

The Inner bar covers the whole of Tablazo Bay and it is approximately 21 kilometers across. Weather on the outer bar is generally rough as waves are built up by the north-easterly wind across the Gulf of Venezuela. On the inner bar it is comparatively calm since it is protected by the chain of islands which form the outer bar.

The first step in the study of the Bar was to form a permanent survey body thich was organized by the joint action of the oil companies in 1923. Surveys nade by this party determined that the natural channel migrated westward and accelerated its movements during certain periods to as much as three feet per lay. In 1935, the channel had reached the extreme western position of its cycle If migration and had deteriorated to the extent that the operations of the shallow draft tankers were seriously handicapped. Records showed that a new :hannel would break through the bar somewhere to the east of the deteriorating :hanne1. This cycle of migration consumed a period of about 20 years.

As oil production increased,the limitation of the bar became more serious. 'he oil companies found that they must open a deeper channel. A model was preparec $y$ the Waterways Experiment Station at Vicksburg, Mississippi, to determine the lost practical route for a dredged channel. The tanker Invercaibo was converted o a seagoing hopper dredge and commenced operations in 1939. Up to 1947, she ompleted and maintained a 20 foot high water channel. At the same time, startng in 1940, a pipe line dredge deepened the 21 kilometer long channel across the nner bar. 


\section{COASTAL ENGINEERING}

Additional hupper dredges assisted the Invercaibo from 1947 to 1949 but it was evident that this channel did not fulfill the needs of navigation into Lake Maracaibo. Several studies of a deep draft channel indicated tha it was posstble but the studies differed in their recommendations and in the estimated cost of the project.

In April 1953, the Venezuela Government initiated a project to provide 35 foot channel through which ocean going vessels could enter and leave the lake unhampered by the former restricted draft. The southern section of the project is a channel 600 feet wide from deep water of the lake to the northe 1 imit of the inner bar, a length of $22.5 \mathrm{kilometers.} \mathrm{In} \mathrm{the} \mathrm{northern} \mathrm{section}$ the channel widens to 1000 feet for $12 \mathrm{kllometers} \mathrm{across} \mathrm{the} \mathrm{outer} \mathrm{bar.} \mathrm{The}$ southern end of the outer channel is protected by a rock breakwater 3.2 kilometers long constructed approximately 1 kilometer east of the channel.

This channel has now been in operation for approximately a year. The channel across the inner bar has been stable and requires only minor dredgi by a pipe line suction dredge to maintain it. The maintenance dredge stertc widening and deepening the channel at the southern end this year as the ner step in providing an outlet from Maracaibo for the still larger tankers ente ing the world pet:oleum txade. As was expected, the outer channel require: constant dredging to maintain its position and depth. The rock breakwater protects the inner part of the channel from the westward drifting sand but there is constant sand encroachment from the east for some three kilometers north of the outer and of the breakwater. The Venezuelan Governmen: expect to maintain this channel and gradually deepens it by an ocean going hopper dredge which is now under design.

The bars have protected Lake Maracaibo from the encroachment of salt water. The opening of a deep channel from the Gulf of Venezuela into the 1 naturally raised questions as to its effect upon the salinity and other characteristics of the lake. Creole is interested in any change in salinit Although our oil fleld organizations use well water for drinking they depen spon lake water for irrigation, sanitation and industrial uses. The lake furnishes fish and shrimp for food. Any change of salinity would directly affect the animal life and would change the incidence of attack from marine borers. One of our major oil field problems is corrosion and it would be aggravated by an increase in the salt content.

In order to be prepared for future changes in the natura conditions, Creole undertook a study of the lake to determine the factors which affect: its salinity, currents, wave action and any other factor which might be dis covered during the work. We requested the Woodshole Oceanographic Institul to make the first studies, set up a program of data gathering, interpret ti data which they obtained and help us form an organization to carry on the work. The study started in April 1953, under the direction of $\mathrm{Dr}$. Alfred i Redfield.

It was thought desirable not only to secure a description of the distribution of salt in the lake as it existed in 1953, but to attempt to dra a consistent picture of the processes, motions and influences which determ this distribution as it exists and as it may vary from time to time. Dr. Redfield's group set up a program to measure water temperature, oxygen, 
GENERAL ASPECTS OF A STUDY ON THE REGIMEN OF LAKE MARACAIBO
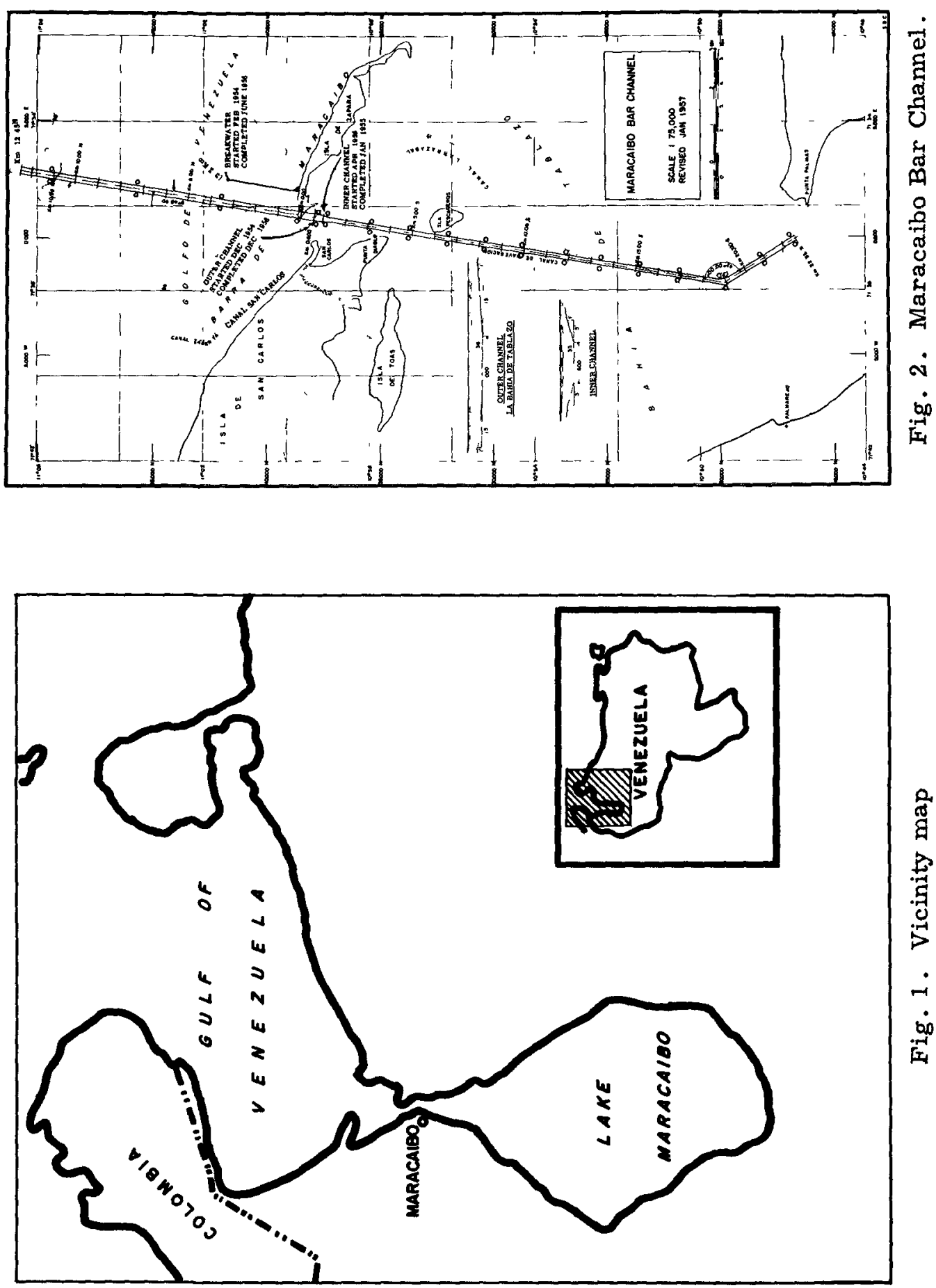
COASTAL ENGINEERING

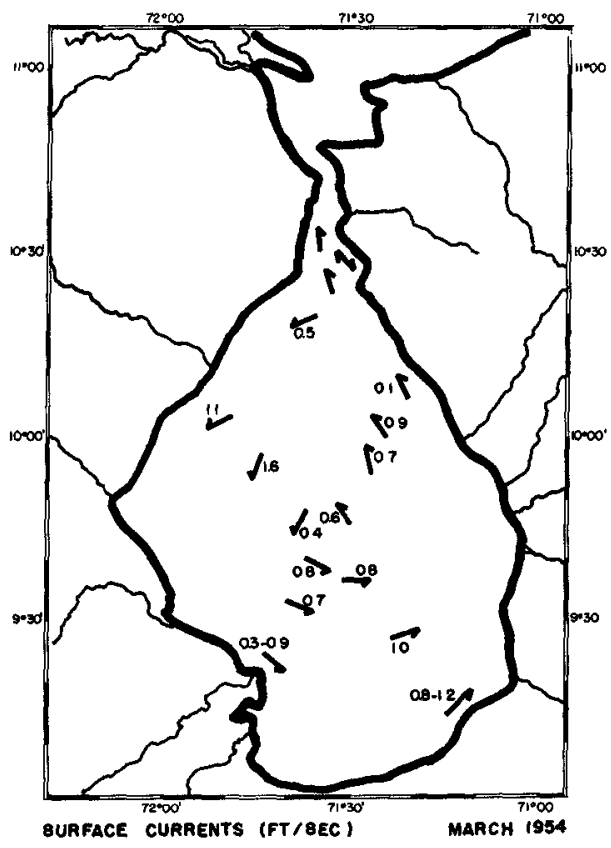

Fig. 3. Surface currents ft. per sec. (March 1954).
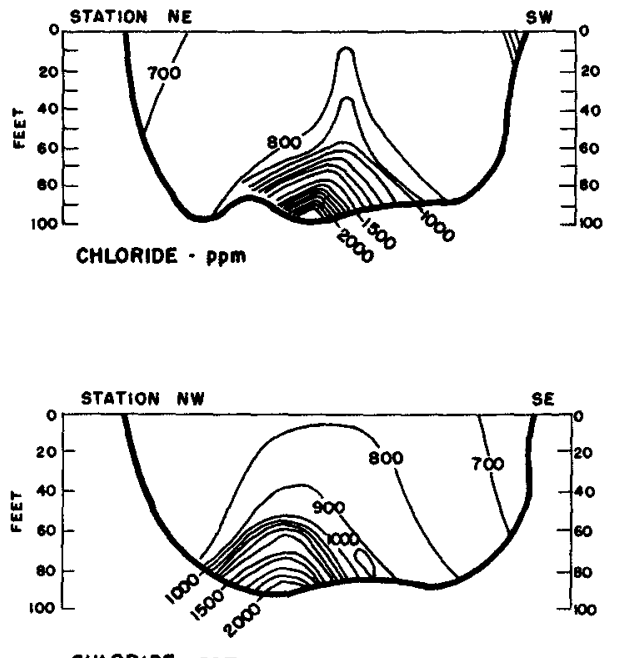
CHLORIDE - PPM

Fig. 5. Chloride concentration with depth

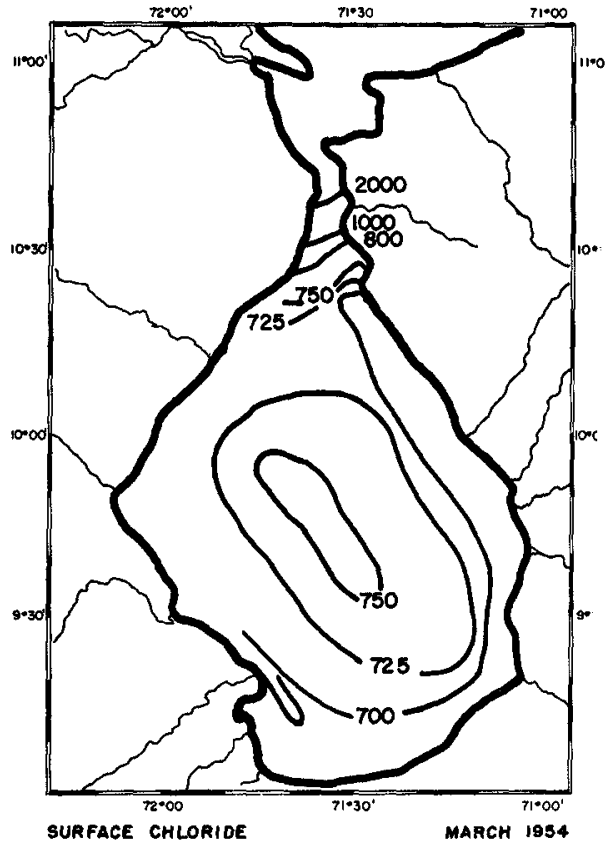

Surface chloride (March 1954)

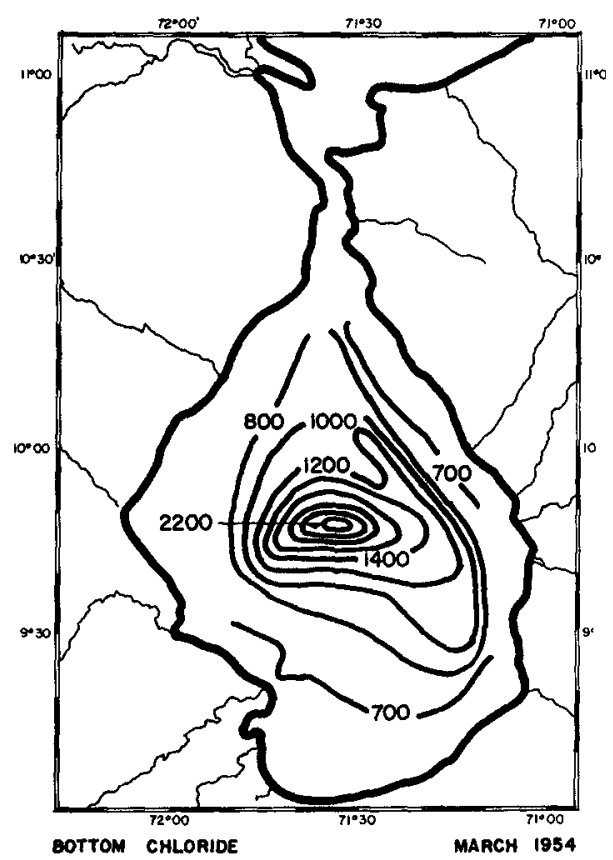

Fig. 6. Bottom chloride (March 1954). 


\section{OF LAKE MARACAIBO}

, hosthorue and chlorides. They also established stations in the strait of Mara to observe tida cycle and the currents. They examined the available data of the salt contunt of the lake at previous times, pertinent information on tides, sea level, rain fall and winds. From this information they set up a program of observations to be made at intervals to provide critical information on the sea sonal and long term change in lake water. After the Spring observations by the representatives of the Woodshole Oceanographic Institution Creole personnel con data gathering until March 1954 when the representatives of wousshole returned for additional observations. Since that time Creole staff has continued to gat data to follow the changes in the lake as they occur.

As might be expected, the study brought forth facts which were a surprise us. It was commonly thought that the chlorides varied from a maximum at the nor of the lake near the entrance to a minimum at the south. Field observations di. not beat this out. The surface chlorides were found to be unfform around the edge of the lake and to increase towards the center. The cause of this distribution was the counter-clock wise circulating current in the lake.

This current is probably caused by the wind. The velocity of the current diminishes from the surface toward the bottom and has a mean value at the surfice of tha order of 0.7 foot per second. At this velocity a particls of watar midway between the center of the lake and the shore would require about 10 days to complete the circuit of the lake. The current appears to fluctuate slightly as the result of semidiurnal tidal components. The velocity declinin as the season advances and may become immeasurable in mid-sumer. Figure 3 show the surface currents, in feet per second, which were measured in March 1954.

The lake contains two distinct classes of water which can be distinguished oy the chloride contant:

A. Lhe Epilimnion, or upper layer, in which the chlorides vary only slightly from place to place, and with deptah.

3. The Hypolimnion, - or deep layer, in which the concentration of chloride is distinctly higher and increase with depth.

The Epilimnion contains the large majority of the lake's water. In 1954 , it constituted $90 \%$ of the volume. Its uniform chloride content indicates that the circulation and the turbulence due to wind-waves are very effective in mixing tha fresh and salt water.

Chemical analyses of the chloride and other salts of the lake water show that the salinity is derived from the waters of the Caribbean Sea.

In 1953/54 the average chloride of the epilimnion was 660 PPM. The mixed water of the epilimnion consequently was a mixture of about one part caribbean sea-water and 30 parts fresh water.

The concentration of chloride in the surface water of the lake, as observed in March 1954, is shown in Figure 4. The chloride is highest at the center of the lake and lowest in a band extending along the shore from the southwest side of the lake ta the northeast. Over a greater portion of the lake's surface the chlorides range from 700 to $750 \mathrm{PPM}$ in 1954, a varlation of $7 \%$. This general distribution of surface chlorides agrees with data collected by early observers and by the Woodishole Survey of 1953. During recent years chlorides in the . Tlimion have ranged from 400 to 1400 PPM. 


\section{COASTAL ENGINEERING}

The more saline water of the hypolimnion occupies a cone with its apex at the center of the lake. The chloride concentration over the bottom of the lake in 1954 is shown in Figure 6 and should be compared with the surface chlorids in Figure 4.

The salt of the hypolimnion originates from sea water which finds it way periodically into the lake from the Gulf of Venezuela. The mixture of sea water and lake water which is produced by tidal mixing along the approaches to the lak has a greater density than the lake water. In entering the lake this water sinks the deeper parts to form the hypolimnion.

The concentration of chloride with depth is shown in Figure 5 representing two sections, made in March 1954, which crossed the lake obliquely at an angle of $60^{\circ}$ from one another. Above the 800 PPM isochlor, the chloride concentration varies very little with depth. Below the point of 800 PPM the chloride increases gradually but at accelerating rate until it exceeds 2000 PPM at the bottom near the center of the lake.

Dr. Redfield suggests the rotary circulation of the lake causes the dense water of the hypolimnion to be spun up into a cone with its apex at the vortex of the eddy. As a result the hypolimnion is withdrawn from the bottom around the margines and the epilimnion occupies the entire water column even to a depth of 100 feet. The epilimnion and hypolimnion mix most intensely in the vortex anc consequently this area is the pricipal source of the salt in the epilimnion and the chlorides in the lake surface are highest in the center. He concludes that the velocity of the lake's circulation is adequate to cause the observed accumulation of denser water of the hypolimnion at the center of the lake.

Between 1954 and 1957 the hypolimnion disappeared completely from Lake Maracaibo. This unexpected phenomenon ocurred during the time that the outer and inner bars were being dredged. Sometime early in 1957, the hypolimnion started to reform as water of higher salt content entered the lake.

The concentration of salt depends upon a balance between the inflow of fresh water from the run off of rain fall, losses to evaporation, and the introduction of salt water from the Gulf of Venezuela by tidal exchange. The salt concentration varies with the seasonal variation in these factors. The stability of the system depends upon the relation between the volume of the lake and the rate of exchange of its water.

A study of the water balance of the Lake Maracaibo Basin by Mr. Douglas $B$. Carter indicates that the mean run off from the land area of the basin nearly equals the evaporation from the lake, approximately $32 \times 10^{9}$ cubic meters per year. The precipitation on the lake proper approximate $22 \times 10^{9}$ cubic meters per year and is of the same order of magnitude as the net volume of fresh water supplied to the lake.

The mean monthly values of the fresh water added to the lake is shown in Figure 7. The mean monthly values of the evaporation from the lake surface are relatively constant throughout the year, but precipitation and run-off vary in such a way that during February, March and April less water is gained than is lost by evaporation.

Changes in tide levels affect the inflow and outflow from the lake but in general terms we can expect that during nine months of the year there will be a net outflow from the lake whereas for three months there will be 
GENERAL ASPECTS OF A STUDY ON THE REGIMEN

OF LAKE MARACAIBO

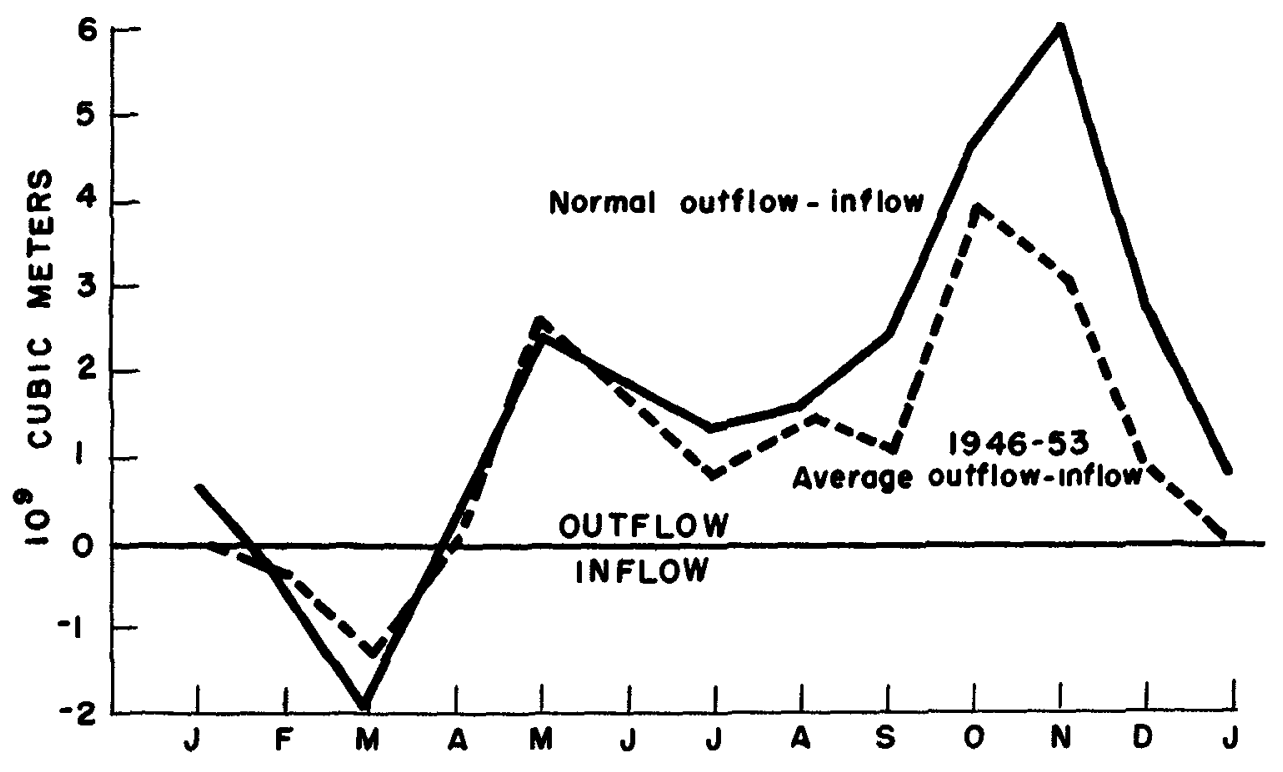

Fig. 7. Outflow and inflow of the Maracaibo basin.

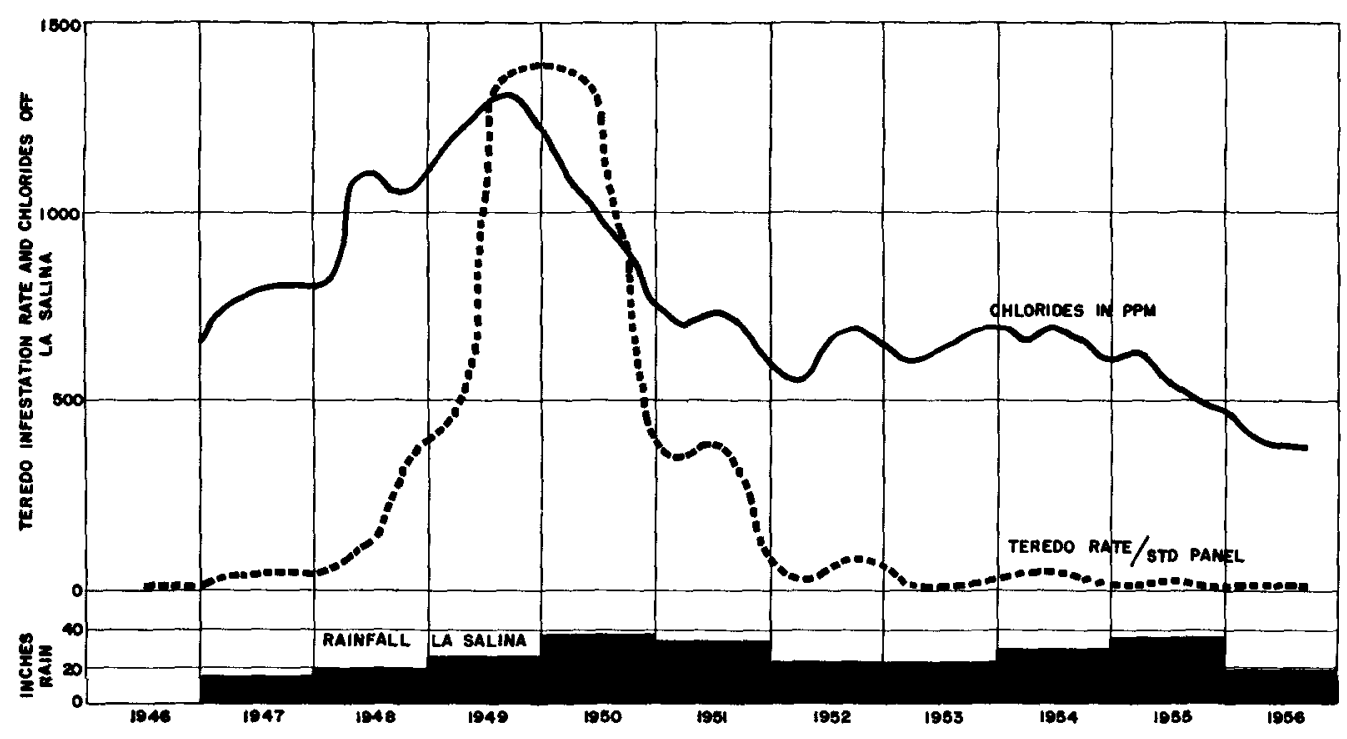

Fig. 8. Relationship between rainfall, salt content and Teredo infestation in Lake Maracaibo. 


\section{COASTAL ENGINEERING}

a net inflow. Our studies have not covered enough years to determine if this cycle is an average or how much it varies from the mean during years of high rain fall and years of low rain fall.

Carter estimates that the exchanged volumes of water are as follows:

Net Accession fresh water

Inflow sea water

outflow lake water

$$
\begin{array}{ccc}
21.34 & 10^{9} & \text { cubic meters per year } \\
3.3 & 10^{9} & \text { cubic meters per year } \\
24.37 & 10^{9} \text { cubic meters per year }
\end{array}
$$

With the knowledge of the mechanics of Lake Maracalbo gained from this excellent study by $\mathrm{Dr}$. Redfield and his associates, we have prepared Figure 8 which shows the relationship between the rain fall, the salt content of the lake, and the attack of teredo Navalis, the marine borer which has caused so much destruction among our marine installations. We are now able to explain some of the anomalies of observed marine borer attack and can understand why materials tested at different times in the lake show varying resistance to marj borers.

It is too early to determine if the dredging of the deep channel through the Maracaibo bar will influence the inflow of the heavier salt water. Any effect of the channel which may have been produced to-date has been masked by a series of rainy years with high run-off. We expect to continue observations to see if a long time trend can be determined. 